\title{
Laser Pressure Cell Transfer Method: A New Microdissection Technique for Frozen Sections
}

Tarou Irié, Tadateru Aida, Mina Aida, Yuki Nagoshi, Reiko Tsuchiya, Gou Yamamoto, Yukiko Maeda, Masako Saito and Tetsuhiko Tachikawa

Department of Oral Pathology, Showa University School of Dentistry, Tokyo, Japan

Irié T, Aida T, Aida M, Nagoshi Y, Tsuchiya R, Yamamoto G, Maeda Y, Saito M and Tachikawa T. Laser pressure cell transfer method: A new microdissection technique for frozen sections. Oral Med Pathol 2004; 9: 53-60, ISSN 1342-0984

Laser microdissection is a method for the procurement of targeted cells from a tissue section, and its use enables one to analyze both nucleic acid and protein from procured cells. However, contamination by cells other than the target cells and damage to mRNA are problems that have been encountered. We have developed a laser pressure cell transfer method that is similar to the laser pressure catapulting method, but it has some advantages with regard to ease of the handling of an original thin film, the procedure for the preparation before laser microdissection, and the use of toluidine blue stain. We demonstrated that the quality of total RNA extracted from procured cells using the laser pressure cell transfer method was excellent for subsequent analysis, and this method could obtain clear morphological images of targeted cells before and after laser microdissection. Furthermore, as trial research for this method, we examined the expression profile of various transcriptional products related to invasive and metastatic potential using surgical materials of oral squamous cell carcinoma (OSCC). Lymph node metastasis tended to be often seen in cases that express VEGF, VEGFC and CD44s ( 2 of 3 cases) and in cases that express vimentin, keratin 19 and osteopontin ( 2 of 3 cases). These findings indicate that there may be a close relationship between those molecules in OSCC. This technique seems to be significantly better than the laser microdissection method currently available for obtaining clear morphological images, preserving the form of procured targeted cells, procuring mRNAs efficiently, and preserving them.

Key words: Laser microdissection, Semiquantitative RT-PCR, Oral squamous cell carcinoma Correspondence: Tarou Irié Department of Oral Pathology, Showa University School of Dentistry, 1-58 Hatanodai, Shinagawa-ku, Tokyo, 142-8555 Japan

Phone: +81-3-3784-8169, Fax: +81-3-3784-2870, E-mail: tarou@dent.showa-u.ac.jp

\section{Introduction}

Various laser microdissection methods have been established (1,2,3). Laser capture microdissection (LCM) used a heat-generating infrared laser to fuse a temperature-sensitive transfer membrane with the underlying histological tissue $(1,2)$. However, LCM could capture only curved or rounded-shaped specimens with diameter of $7.5 \mu \mathrm{m}$ and beyond due to the physical properties of the laser, and it had difficulty in procuring peaked and angleshaped specimens (4). A problem occasionally encountered in LCM is failure to remove the selected cells from the slide because of incomplete tissue dehydration or a laser setting that is too low for complete permeation of the melted polymer from transfer membrane into the section. On the other hand, increased adherence of the section to the slide could prevent the removal of the targeted cells. This was suggested as a cause of contamination of RNAs from non-targeted cells in LCM (5). A method less commonly used for laser microdissection is the laser pressure catapulting (LPC) method, which uses a laser not only to microdissect but also to transfer the targeted cells directly into the cap of a microfuge tube. This method avoids mechanical contact, such as a temperature-sensitive transfer membrane, to capture clean samples of any shape. But it has been assumed that the LPC method is more time consuming and requires greater skill (5).

We have developed a laser pressure cell transfer (LPCT) method similar to the LPC method, but it has some advantages with regard to ease of handling of the original thin film that we use, the procedure for the preparation before laser microdissection, and the use of toluidine blue stain. This method could solve the problems mentioned above. In this study, we demonstrate that the LPCT method enables us to obtain clear morphological 
images of targeted cells before and after laser microdissection, and offers excellent procuring efficiency of RNA. Furthermore, as trial research for the demonstration of applicability of our new laser microdissection method to clinicopathological analysis using surgical materials of oral squamous cell carcinoma (OSCC), we examined the expression profile of various transcriptional products, such as vascular endothelial growth factor (VEGF) (6), vascular endothelial growth factor B (VEGFB) (7), vascular endothelial growth factor C (VEGFC) (7), vascular endothelial growth factor receptor 1 (VEGFR-1) (8), CD44 standard form (9), CD44 variant form (9), matrix metalloproteinases (MMPs) $(10,11)$, osteopontin (12), keratin $19(13,14)$ and vimentin $(15)$ that could be a prognostic factors indicative of the invasive and metastatic potential.

\section{Materials and methods}

Data of samples

Specimens of primary OSCC from five patients were used for the present analysis (Table 1). Four patients were male and one patient was female. The range of patients' ages was 58-80 years (mean $=68$ years). Lymph node metastasis was detected at the time of surgery in three patients. Histologically, three OSCCs were moderately differentiated and two were well differentiated.

Preparation of frozen fixed samples and laser microdissection (LPCT method)

Tissue sampled from resected materials were embedded in OCT compound and frozen in isopentane cooled in liquid nitrogen. The frozen blocks were sliced by a cryomicrotome at a thickness of $8 \mu \mathrm{m}$, and each tissue section was affixed to a slide to which an original thin film (provided by Meiwa Shoji Co, LTD, Tokyo, Japan) had been attached by silicone adhesive (GE Toshiba Silicone, Tokyo, Japan) (Fig. 1). Slice samples were stored at $-40^{\circ} \mathrm{C}$ until use.

The sliced sample was quickly fixed in $100 \%$ methanol for 3 minutes, and then returned to room temperature and stained with $1 \%$ toluidine blue solution. Laser Scissors 390/20 (Cell Robotics, Inc., Albuquerque, NM, USA) using $337 \mathrm{~nm}$ nitrogen laser was used for laser

Table 1: Clinicopathological data of five cases of OSCC

\begin{tabular}{|c|c|c|c|c|c|}
\hline & Age & Sex & Site & Lymph node metastasis & Differentiation \\
\hline Case 1 & 69 & Female & Gingiva & Positive & Moderate \\
\hline Case 2 & 80 & Male & Gingiva & Positive & Well \\
\hline Case 3 & 58 & Male & Floor of the mouth & Negative & Moderate \\
\hline Case 4 & 63 & Male & Gingiva & Positive & Well \\
\hline Case 5 & 71 & Male & Buccal mucosa & Negative & Moderate \\
\hline
\end{tabular}

Object slide

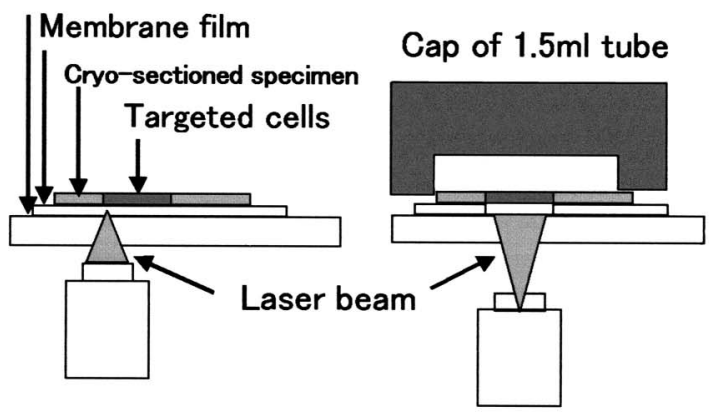

Objective lens

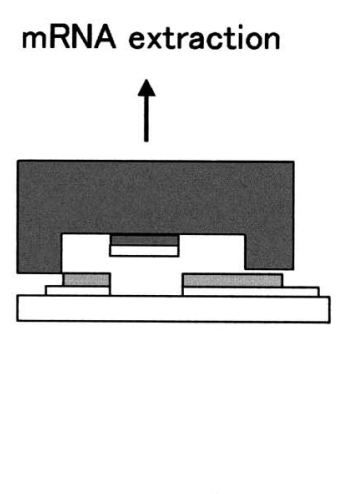

mRNA extraction

Fig. 1: Diagram of laser pressure cell transfer method. 
microdissection. We procured one- or two-hundred cells from cancer tissues and normal mucosal epithelia in each OSCC case for analysis of expression profiling of mRNA related to invasive and metastatic potential.

\section{RNA extraction from microdissected samples}

Total RNA was independently extracted from each population of laser-microdissected cells. Briefly, the microdissected cells within the cap were covered with 200 $\mu 1$ buffer solution, $4 \mathrm{M}$ guanidine thiocyanate, $25 \mathrm{mM}$ sodium citrate, and $0.5 \%$ sarcosyl, and the cap was placed on the tube and vortexed. After the addition of $20 \mu \mathrm{l}$ of 2 M sodium acetate, $220 \mu \mathrm{l}$ of water-saturated phenol and $60 \mu \mathrm{l}$ of chloroform-isoamyl alcohol, the tube was centrifuged at $10000 \mathrm{~g}$ at $4{ }^{\circ} \mathrm{C}$ for 30 minutes to separate the aqueous and organic phases. The aqueous layer was transferred to a new tube. Two $\mu \mathrm{l}$ of glycogen and $200 \mu \mathrm{l}$ of isopropanol were added and centrifuged at $10000 \mathrm{~g}$ at 4 ${ }^{\circ} \mathrm{C}$ for 30 minutes. After removing the majority of the supernatant, the pellet was washed with $70 \%$ ethanol. After the pellet was centrifuged and air-dried, the mRNA was resuspended in RNase-free water.

\section{Quantitative analysis of the quality of extracted RNA}

The quality of extracted RNA was examined by Agilent 2100 Bioanalyzer (Agilent Technologies, Tokyo, Japan) and the RNA 6000 Pico Assey (Agilent Technolo- gies, Tokyo, Japan). Each $1 \mu$ l of extracted total RNA from about one thousand procured cells was added into the well of the LabChip of RNA 6000 Pico Assey. The LabChip was placed in the Agilent 2100 Bioanalyzer and analysed.

\section{Reverse transcription polymerase chain reaction (RT-PCR)}

Before making a semiquantitative analysis of the transcriptional product, the kinetics of using primers were examined and it was indicated that 35 cycles of PCR for each primer would avoid any plateau effect (16). Reverse transcription used $25 \mathrm{uM}$ Oligo(dT)20, $25 \mathrm{ng} / \mathrm{l}$ random hexamer oligonucleotides, $50 \mathrm{mM}$ Tris acetate ( $\mathrm{pH} 8.4$ ), $75 \mathrm{mM}$ potassium acetate, $8 \mathrm{mM}$ magnesium acetate, $4 \mathrm{U}$ RNase inhibitor, 0.01M DTT, $2 \mathrm{mM}$ dNTP and avian RNase H-minus reverse transcriptase (Invitrogen Corp, Carlsbad, CA, USA) for $60 \mathrm{~min}$ at $50^{\circ} \mathrm{C}$. The resulting firststrand cDNA was diluted and used as a template for PCR analysis. PCR reactions were performed in $25 \mu \mathrm{l}$ PCRMix consisting of GeneAmp 1x PCR Gold Buffer (Perkin Elmer, Norwalk, CT, USA), $1.5 \mathrm{mM} \mathrm{MgCl}_{2}, 200 \mu \mathrm{M}$ dNTP and 0.125 Unit of AmpliTaq Gold (Perkin Elmer, Norwalk, CT, USA). Amplification was carried out under the following conditions: $10 \mathrm{~min}$ at $95^{\circ} \mathrm{C}$; 35 cycles of 1 min at 94 ${ }^{\circ} \mathrm{C}, 1 \mathrm{~min}$ at $55^{\circ} \mathrm{C}$ and $1 \mathrm{~min}$ at $72^{\circ} \mathrm{C}$; followed by $7 \mathrm{~min}$ at $72^{\circ} \mathrm{C}$. The sequences of the PCR primer pairs that were used for each gene are as follows: human beta-actin (17),
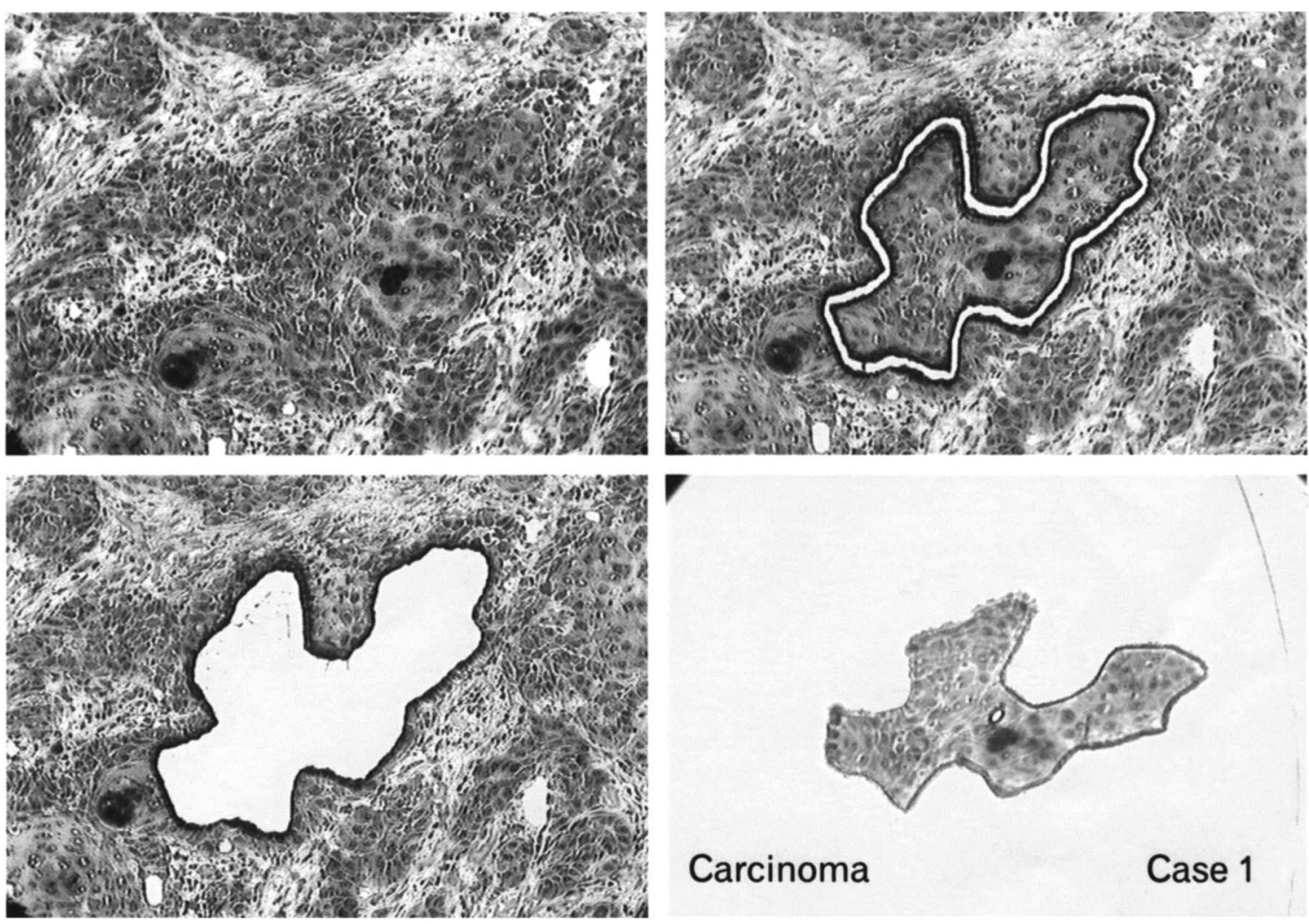

\section{Carcinoma}

Case 1

Fig. 2: Procurement of OSCC cells in Case 1 using laser microdissection (laser pressure cell transfer type). Specimen before (upper left) and after laser microdissection (upper right, lower left) and after laser pressure cell transfer (lower right). 


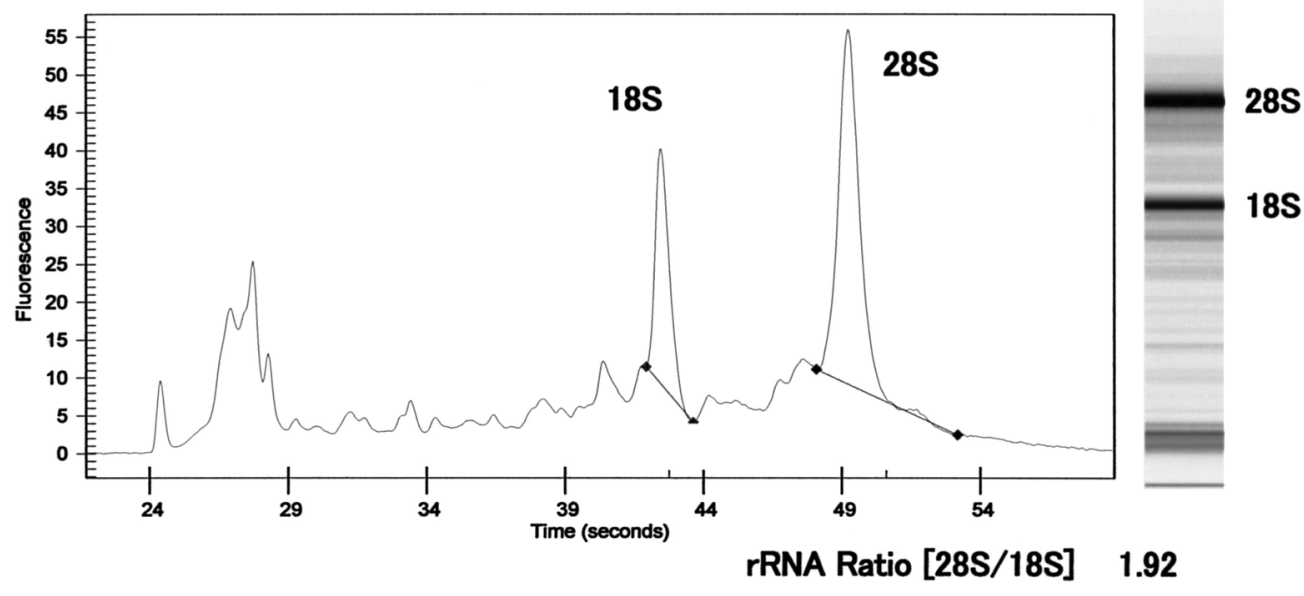

Fig. 3: Electronpherogram of extracted total RNA from about one thousand procured cells using Agilent 2100 Bioanalyzer (left). Gel-like view of this analysis (right).

Table 2: Expression profile of mRNAs in OSCC by semiquantitative analysis

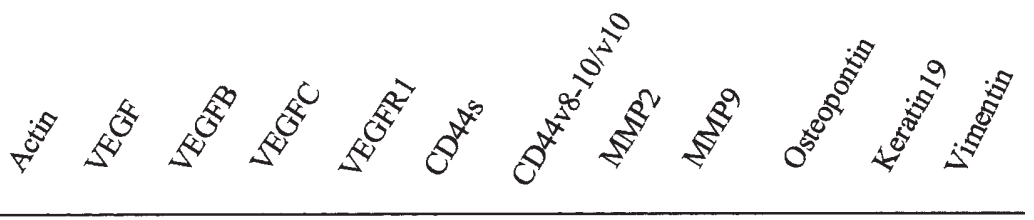

$\begin{array}{lllllllllllll}\text { Case } 1 & 1 & \underline{0.81} & - & \underline{0.81} & \text { nd } & \underline{0.52} & \underline{0.35} & \text { nd } & \underline{0.27} & \underline{0.58} & \underline{0.20} & \underline{0.30} \\ \text { Case } 2 & 1 & \text { nd } & \text { nd } & \text { nd } & \text { nd } & \underline{0.36} & \text { nd } & \text { nd } & \text { nd } & \underline{0.56} & \underline{0.23} & \underline{0.43} \\ \text { Case 3 } & 1 & \text { nd } & \text { nd } & \text { nd } & \text { nd } & \text { nd } & \text { nd } & \text { nd } & \text { nd } & \underline{1.26} & \underline{0.65} & \underline{0.50} \\ \text { Case } 4 & 1 & \underline{0.26} & - & \underline{0.44} & \text { nd } & \underline{0.77} & \underline{0.60} & \text { nd } & \text { nd } & \text { nd } & \text { nd } & \text { nd } \\ \text { Case } 5 & 1 & \underline{0.30} & - & \underline{1.28} & \text { nd } & \underline{1.62} & \underline{0.39} & \text { nd } & \text { nd } & \text { nd } & \underline{0.30} & \text { nd }\end{array}$

nd; not detected.

5'CAC TGT GTT GGC GTA CAG GT, 5'-TCA TCA CCA TTG GCA ATG AG; vascular endothelial growth factor (VEGF) (18), 5'-TTC CAG GAG TAC CCT GAT GAG, 5'GGC TCA CCG CCT CGG CTT GTC; vascular endothelial growth factor B (VEGFB) (19), 5'-GAT CCA GTA CCC GAG CAG TC, 5'-GCA CCT ACA GGT GTC TGG GT; vascular endothelial growth factor C (VEGFC) (18), 5'-AAT GTG GGG CCA ACC GAG AA, 5'-CCA ATA TGA AGG GAC ACA ACG; vascular endothelial growth factor receptor 1 (VEGFR-1) (18), 5'-TCT TGA CCC ACA TTG GCC AC, 5'-TCG CTG CTG GTG ACG CTA TC; CD44 standard form (CD44s) (20), 5'-CCG CTA TGT CCA GAA AGG AG, 5'-GGG TGG AAT GTG TCT TGG TC; CD44 variant isoform (CD44v8-10/v10) (9), 5'-GAC AGA ATC CCT GCT ACC AAT A, 5'-ATG TGT CTT GGT CTC CTG ATA A; matrix metalloproteinase 2 (MMP2) (21), 5'-GCG GAT CCA GAG CCC AGA GAG ACA C, 5'-TTA GGA CGG GCC
TCA CCT TCG AAT T; MMP9 (21), 5'-TGG ACG ATG CCT GCA ACG TG, 5'-GTC GTG CGT GTC CAA AGG CA; osteopontin (22), 5'-CCA AGT AAG TCC AAC GAA AG, 5'-GGT GAT GTC CTC GTC TGT A; keratin 19 (17), 5'AGG TGG ATT CCG CTC CGG GCA, 5'-ATC TTC CTG TCC CTC GAG CA; vimentin (23), 5'-AGA TGC GTG AAA TGG AAG AG, 5'-AGG GAG GAA AAG TTT GGA AG. All primers were selected from 2 different exons with at least 1 intervening intron. PCR products were visualized by $2 \%$ agarose gel electrophoresis using 100 bp DNA Ladder (Invitrogen Corp, Carlsbad, CA, USA) and SYBR Green Nucleic Acid Gel Stain (Molecular Probes Inc, Eugene, OR, USA) using FluoroImager585 (Molecular Dynamics Inc, Tokyo, Japan). Relative amounts of the each PCR product were compared with beta-actin in each case using ImageQuantNT (Molecular Dynamics Inc, Tokyo, Japan). 


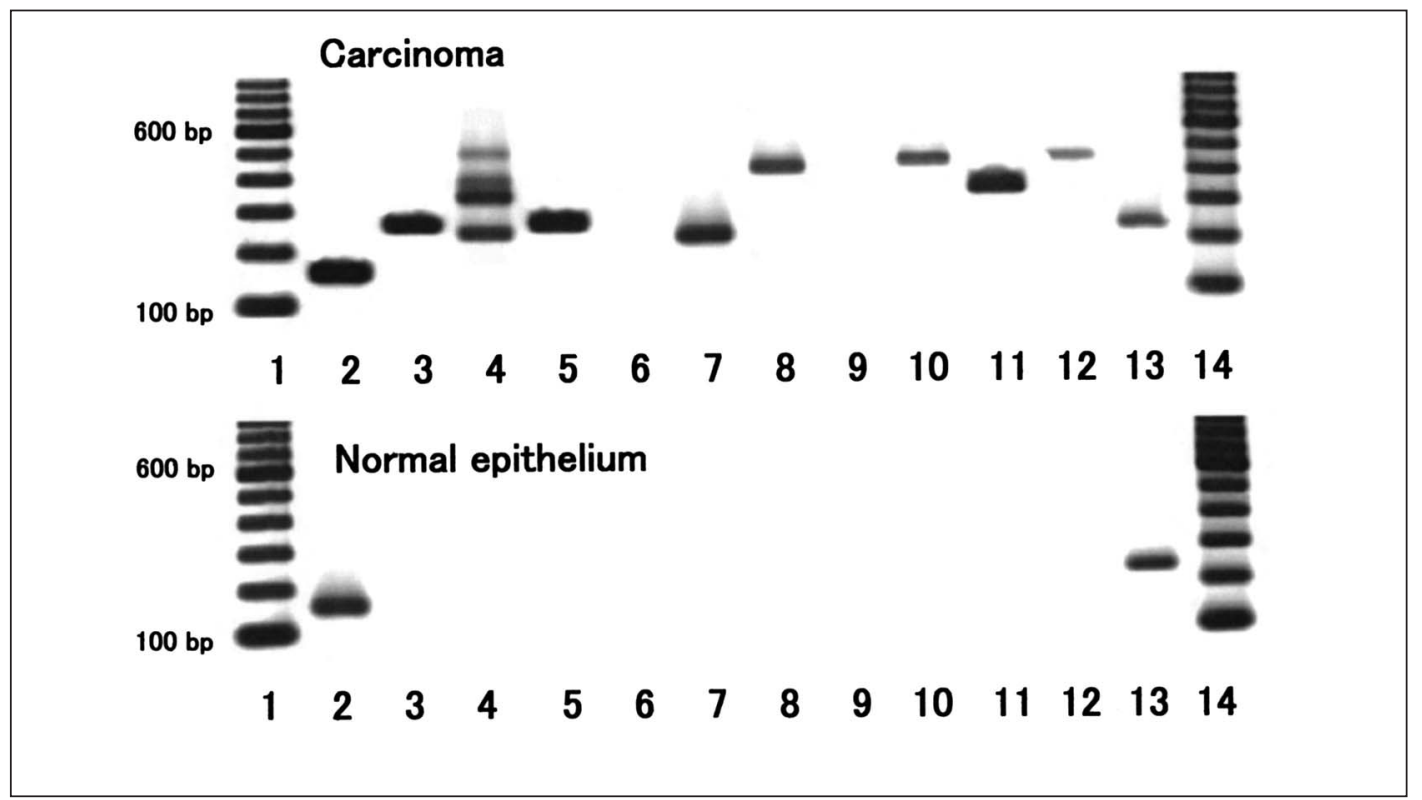

Fig. 4: Expression profile of mRNAs in Case 1 in OSCC (upper panel) and normal mucosal epithelium (lower panel). Lane 1: 100 bp DNA ladder, 2: Actin, 3: VEGF, 4: VEGFB, 5: VEGFC, 6: VEGFR1, 7: CD44s, 8: CD44v8-10/v10, 9: MMP2, 10: MMP9, 11: Osteopontin, 12: Keratin19, 13: Vimentin, 14: 100bp DNA ladder

Table 3: Advantages and disadvantages of representative laser microdissection methods

LCM
Advantage

Rapid collection of large amount of tissue (5)

Disadvantage

Dehydration can not be omitted.

Optical resolution of dehydrated tissue sections without coverslip is not sufficient (5).

Small cells may be difficult to isolate without contaminating fragments of adjacent cells due to minimun laser spot size or insufficient dehydration (5).
Single cells or small tissue areas of any size or shape can be collected (4).

Contact-free collection of tissue fragments in the cap of a microcentrifuge tube (5).

LPC can be more time consuming and requires greater skills $(5)$.

The handling of membrane is difficult due to its thinness.
Single cells or small tissue areas of any size or shape can be collected.

Contact-free collection of tissue fragments in the cap of a microcentrifuge tube.

The handling of membrane is good

Clear morphological image can be obtained with toluidine blue staining

LPCT may be more time consuming in collection of large amount tissue.

\section{Results}

Quality of the morphological images of targeted cells before and after laser microdissection, and procurement efficiency of RNA using LPCT method

Commercially available Laser Scissors 390/20 (Cell Robotics, Inc., Albuquerque, NM, USA) was used for this analysis. With the high photonic energy of the focused UV laser, the targeted cells were precisely circumscribed in order to isolate them from the surrounding tissue (Fig. 2). Circumscription of the targeted cells resulted in a gap. The width of the gap was between 0.5 and 20 microns, depending on the objective lens and lens opening. The morphology of the toluidine blue stained tissue was extremely clear and remained entirely intact before and after procurement of the targeted cells. In observation using the specimens which were not covered with coverslip, the quality of morphological image of toluidine blue stained tissues were better than that of hematoxylin-eosin (H \& E) stained ones.

For the evaluation of the quality of extracted RNA from procured cells, we procured about one thousand cells from frozen sections (5 cases). Electronpherogram using Agilent 2100 Bioanalyzer showed that there is absence of large well-defined peaks between the two ribosomes 
(18S and 28S) and the baseline between 29 seconds and $18 \mathrm{~S}$ ribosome is free of remarkable large peaks (Fig. 3). The maximum ratio of two rRNA bands (18S and 28S) was 1.92 . The average ratio was 1.60 in 5 cases. These results showed that the quality of total RNA extracted from procured cells was excellent for subsequent analysis.

Expression profiling of $m R N A$ related to invasive and metastatic potential in oral squamous cell carcinoma

Table 2 summarizes the results of present semiquantitative analysis on the expression of transcriptional products related to invasive and metastatic potential in OSCC in each case. Since the expression of various transcriptional products were clearly demonstrated in the cancer tissues and none of the transcriptional products other than beta-actin (Case 1-5) and vimentin (Case 1) were expressed in the normal mucosal epithelium (Fig. 4), we compared the expression level of these transcriptional products in OSCC semiquantitatively with the level of beta-actin in each case. The relative expression levels of various transcriptional products compared to that of beta-actin were from 0.2 to 1.62 , varying from case to case. In this result, VEGF and VEGFC were expressed in three cases (Cases 1, 4, 5) and all of these cases were also expressed CD44s and CD44v8-10/v10. Vimentin was expressed in three cases (Cases 1, 2,3) and all these cases also expressed keratin 19 and osteopontin. Our results showed lymph node metastasis tended to be often seen in cases that expressed VEGF, VEGFC and CD44s (2 of 3 cases) and in cases that expressed vimentin, keratin 19 and osteopontin ( 2 of 3 cases). The primer pair of CD44v8$10 /$ v10 used in this analysis could competitively amplify CD44v8-10 and CD44v10 simultaneously (4), allowing us to compare their relative amounts. We detected CD44v10 in two cases (Cases 4, 5) and CD44v8-10 in one case (Case 1).

\section{Discussion}

LPCT method

We demonstrated that LPCT method enabled us to obtain clear morphological images of targeted cells before and after laser microdissection and excellent procuring efficiency of RNA. We succeeded in detecting several kinds of transcriptional products from only 10 cells using this method in a previously reported experiment (24). Such advantages of laser pressure cell transfer method compared with other laser microdissection systems were caused by four major characteristic points. First was the use of an original thin film. This film that we found out did not wrinkle easily and had tolerance to heat and reagents for RNA extraction. This characteristic of the thin film provided clear morphological images of targeted cells and procuring efficiency of RNA. The LPCT method did not require the film to be turned upside down unlike in the LPC method. By omitting this step, our method was less time consuming and it did not require as great a skill.
Second was the use of toluidine blue stain. Staining could be completed in one short step and was made by a few reagents. The character of toluidine blue staining was an important factor reducing the opportunity for degradation of mRNA, and it seemed to avoid contamination of ribonuclease into the staining solution. Third was a noncontact manner for the procurement procedure. LPCT method enabled us to procure targeted cells without contact with any kind of materials except for the reagent of fixation and toluidine blue stain. Procured targeted cells were directly put into the cap of the $1.5 \mathrm{ml}$ tube and were lysed for extraction of RNA at the same time. The character of this procedure of LPCT method reduces opportunity for the degradation of RNA. Fourth was the use of $337 \mathrm{~nm}$ nitrogen laser. The mechanism of this method using $337 \mathrm{~nm}$ nitrogen laser is considered to be a photodecomposition process without heating. The $337 \mathrm{~nm}$ wavelength does not introduce single-strand breaks into DNA (25). These effects seem to avoid damage to the nucleic acid. Table 3 summarizes advantages and disadvantages of representative laser microdissection methods. The greatest difference between the LPCT method and the LPC method are our use of an original thin film, the use of toluidine blue stain, and our procedure for handling after affixture of cryosection to this film. This thin film is different in thickness and constitution from that used in the LPC method. During handling, the LPCT method did not require the film to be turned upside down unlike in the LPC method.

This technique seems to be significantly better than the laser microdissection method currently available for obtaining clear morphological images, preserving the form of procured targeted cells, procuring mRNAs efficiently and preserving them.

Expression profiling of $m R N A$ related to invasive and metastatic potential in oral squamous cell carcinoma

As trial research for demonstration of applicability of our new laser microdissection method to clinicopathological analysis, we examined the expression profile of various transcriptional products, such as VEGF, CD44 standard form, CD44 variant form, MMP2, 9, osteopontin, keratin 19 and vimentin that could be a prognostic factors indicative of the invasive and metastatic potential. In our results, cases that expressed VEGF, VEGFC tended to express CD44s and CD44v8-10/v10. Moreover, a similar tendency was noted for vimentin, keratin 19 and osteopontin (Table 2). VEGF had been reported to upregulate CD44 expression on human endothelial cell (26), and up-regulation of VEGF and VEGFC had predictive value for the presence of cervical nodal metastases of head and neck squamous cell carcinoma (27). On the other hand, both vimentin and osteopontin expression have been associated with breast cancer invasion and metastasis (28). Moreover HER2 (c-erbB-2) 
overexpression significanfly correlated with keratin 19 and vimentin (29). It has been suggested that HER2 overexpression might provide worse prognostic information in breast cancer patients. Our results showed lymph node metastasis tended to be seen in cases that expressed VEGF, VEGFC and CD44s (2 of 3 cases) and in cases that expressed vimentin, keratin 19 and osteopontin (2 of 3 cases), and it might indicate that there was a close relationship between those molecules in OSCC.

The primer pair of CD44 variant isoform used in this analysis could competitively amplify CD44v8-10 and CD44v10 simultaneously (9), allowing us to compare their relative amounts. We detected CD44v10 in two cases (Case $4,5)$ and CD44v8-10 in one case (Case 1). The expression of CD44v10 was recognized in non-cancerous tissue of the urinary bladder. However, in urinary bladder carcinoma, CD44v8-10 was expressed in greater amounts than CD44v10 (30). This finding is in contrast to our results and may indicate that there is a difference in the expression significance of the CD44 variant form between OSCC and cancers of other organs.

In conclusion, we clearly demonstrated that RNAs of various factors with excellent quality could be detected effectively in frozen sections of surgical materials. This laser microdissection system using LPCT method might have possibility to enable us to evaluate the degree of malignancy and prognosis of OSCC patients in routine pathological diagnosis.

\section{Acknowledgments}

This work was supported in part by Grants-in-Aid for Scientific Research and High-Technology Center Project from Ministry of Education, Culture, Sports, Science and Technology in Japan.

\section{References}

1. Emmert-Buck MR, Bonner RF, Smith PD, et al. Laser capture microdissection. Science 1996; 274: 998-1001.

2. Bonner RF, Emmert-Buck M, Cole K, et al. Laser capture microdissection: molecular analysis of tissue. Science 1997; 278: 1481-3.

3. Schütze K, Pösl H and Lahr G. Laser micromanipulation systems as universal tools in cellular and molecular biology and in medicine. Cell Mol Biol 1998; 44: 735-46.

4. Schütze K and Lahr G. Identification of expressed genes by laser mediated manipulation of single cells. Nature Biol 1998; 16: $737-42$.

5. Fend F and Raffeld M. Laser capture microdissection in pathology. J Clin Pathol 2000; 53: 666-72.

6. Gasparini G, Toi M, Verderio P, et al. Prognostic significance of p53, angiogenesis, and other conventional features in operable breast cancer: subanalysis in node-positive and nodenega-tive patients. Int J Oncol 1998; 12: 1117-25.

7. Gunningham SP, Currie MJ, Han C, et al. Vascular endothe- lial growth factor-B and vascular endothelial growth factor$\mathrm{C}$ expression in renal cell carcinomas: regulation by the von Hippel-Lindau gene and hypoxia. Cancer Res 2001; 61: 320611.

8. Bunone G, Vigneri P, Mariani L, et al. Expression of angiogenesis stimulators and inhibitors in human thyroid tumors and correlation with clinical pathological features. Am J Pathol 1999; 155: 1967-76.

9. Okamoto I, Morisaki T, Sasaki J, et al. Molecular detection of cancer cells by competitive reverse transcription-polymerase chain reaction analysis of specific CD44 variant RNAs. J Natl Cancer Inst 1998; 90: 307-15.

10. Ueno H, Nakamura H, Inoue M, et al. Expression and tissue localization of membrane-type 1, 2 and 3 matrix metalloproteinases in human invasive breast carcinomas. Cancer Res 1997; 57: 2055-60.

11. Hong SD, Hong SP, Lee JI, et al. Expression of matrix metalloproteinase- 2 and -9 in oral squamous cell carcinomas with regard to the metastatic potential. Oral Oncol 2000; 36: $207-13$.

12. Behrend EI, Craig AM, Wilson SM, et al. Reduced malignancy of ras-transformed NIH 3T3 cells expressing antisense osteopontin RNA. Cancer Res 1994; 54: 832-7.

13. Lindberg K and Rheinwald JG. Suprabasal $40 \mathrm{kd}$ keratin (K19) expression as an immunohistologic marker of premalignancy in oral epithelium. Am J Pathol 1989; 34: 8998.

14. Crowe DL, Milo GE and Shuler CF. Keratin 19 downregulation by oral squamous cell carcinoma lines increases invasive potential. J Dent Res 1999; 78: 1256-63.

15. de Araujo VC, Pinto Junior DS, de Sousa SO, et al. Vimentin in oral squamous cell carcinoma. Eur Arch Otorhinolaryngol 1993; 250: 105-9.

16. Yokoi H, Natsuyama S, Iwai M, et al. Non-radioisotopic quantitative RT-PCR to detect changes in mRNA levels during early embryo development. Biochem Biophys Res Commun 1993; 195: 769-75.

17. Noguchi S, Aihara T, Motomura K, et al. Histologic characteristics of breast cancers with occult lymph node metastases detected by keratin 19 mRNA reverse transcriptase-polymerase chain reaction. Cancer 1996; 78: 1235-40.

18. Bunone G, Vigneri P, Mariani L, et al. Expression of angiogenesis stimulators and inhibitors in human thyroid tumors and correlation with clinical pathological features. Am J Pathol 1999; 155: 1967-76.

19. Decker MML, Karperien M, Bent CVD, et al. Expression of vascular endothelial growth factors and their receptors during osteoblast differentiation. Endocrinology 2000; 141: 166774.

20. Gu J, Daa T, Kashima K, et al. Expression of splice variants of CD44 in thyroid neoplasms derived from follicular cells. Pathol Int 1998; 48: 184-90.

21. Forsyth PA, Wong H, Laing TD, et al. Gelatinase-A (MMP-2), gelatinase-B (MMP-9) and membrane type matrix metalloproteinase-1 (MT1-MMP) are involved in different 
aspects of the pathophysiology of malignant gliomas. $\mathrm{Br} J$ Cancer 1999; 79: 1828-35.

22. Rickard DJ, Kassem M, Hefferan TE, et al. Isolation and characterization of osteoblast precursor cells from human bone marrow. J Bone Miner Res 1996; 11: 312-24.

23. Perreau J, Lilienbaum A, Vasseur M, et al. Nucleotide sequence of the human vimentin gene and regulation of its transcription in tissues and culture cells. Gene 1998; 62: 716.

24. Niino YS, Irie T, Takaishi M, et al. PKC $\theta$ II, a new isoform of PKC specifically expressed in testis. J Biol Chem 2001; 276: 36711-7.

25. deWitt A and Greulich G. Wavelength dependence of laserinduced DNA damage in lymphocytes observed by singlecell gel electrophoresis. J Photochem Photobiol Biol 1995; 30: 71-6.

26. Griffioen AW, Coenen MJ, Damen CA, et al. CD44 is involved in tumor angiogenesis; an activation antigen on human endothelial cells. Blood 1997; 90: 1150-9.

27. O-charoenrat P, Rhys-Evans $P$ and Eccles SA. Expression of vascular endothelial growth factor family members in head and neck squamous cell carcinoma correlates with lymph node metastasis. Cancer 2001; 92: 556-68.

28. Sung V, Gilles C, Murray A, et al. The LCC15-MB human breast cancer cell line expresses osteopontin and exhibits an invasive and metastatic phenotype. Exp Cell Res 1998; 241: 273-84.

29. Kruger S, Weitsch G, Buttner H, et al. HER2 overexpression in muscle-invasive urothelial carcinoma of the bladder: prognostic implications. Int $J$ Cancer 2002; 102: 514-8.

30. Miyake H, Okamoto I, Hara I, et al. Highly specific and sensitive detection of malignancy in urine samples from patients with urothelial cancer by CD44v8-10/CD44v10 competitive RT-PCR. Int J Cancer 1998; 79: 560-4. 